\title{
Identification of a New Hereditary Amyloidosis Prealbumin Variant, Tyr-77, and Detection of the Gene by DNA Analysis
}

\author{
Margaret R. Wallace, Francis E. Dwulet, Eliot C. Williams, ${ }^{\star}$ P. Michael Conneally, and Merrill D. Benson \\ Departments of Medical Genetics, Medicine, and Biochemistry, Indiana University School of Medicine, Indianapolis, Indiana 46223, \\ Rheumatology Section, Richard L. Roudebush Veterans Administration Medical Center, Indianapolis, Indiana 46202; \\ and ${ }^{*}$ Departments of Medicine and Pathology, University of Wisconsin, Madison, Wisconsin 53706
}

\begin{abstract}
In the last several years, five human plasma prealbumin (transthyretin) variants have been discovered in association with hereditary amyloidosis, a late-onset fatal disorder. We recently studied a patient of German descent with peripheral neuropathy and bowel dysfunction. Biopsied rectal tissue contained amyloid that stained with anti-human prealbumin. Amino acid sequence analysis of the patient's plasma prealbumin revealed both normal and variant prealbumin molecules, with the variant containing a tyrosine at position 77 instead of serine. We predicted a single nucleotide change in codon 77 of the variant prealbumin gene, which we then detected in the patient's DNA using the restriction enzyme SspI and a specifically tailored genomic prealbumin probe. DNA tests of other family members identified several gene carriers. This is the sixth prealbumin variant implicated in amyloidosis, and adds to the accumulating evidence that the prealbumin amyloidoses are more varied and prevalent than previously thought.
\end{abstract}

\section{Introduction}

The autosomal-dominant amyloidoses are characterized by gradual systemic amyloid deposition beginning in adulthood and resulting in progressive dysfunction of surrounding tissues, which leads to death (1). Although the symptoms and age of onset can vary, most forms of this disease are accompanied by peripheral neuropathy, and are therefore grouped under the name "familial amyloidotic polyneuropathy" (FAP). ${ }^{1}$ To date, the protein most often found involved in the disease is prealbumin (transthyretin), a plasma transport protein with a 127amino acid monomer (2). Prealbumin, synthesized in the liver throughout life, circulates as a homotetramer and transports retinol-binding protein (RBP) and thyroxine (3). Within the past few years, five prealbumin variants, each containing a single amino acid substitution, have been discovered in associ-

This work was presented in part at the American Society of Human Genetics Annual Meeting, Philadelphia, and as an abstract (1986. Am. J. Hum. Genet. 39:22).

Address reprint requests to Dr. M. D. Benson, Chief, Rheumatology Section, A772, Richard L. Roudebush Veterans Administration Medical Center, 1481 W. 10th St., Indianapolis, IN 46202. 1987.

Received for publication 3 April 1987 and in revised form 30 July

1. Abbreviations used in this paper: FAP, familial amyloidotic polyneuropathy; RBP, retinol-binding protein; RFLP, restriction fragment length polymorphism.

J. Clin. Invest.

(c) The American Society for Clinical Investigation, Inc.

0021-9738/88/01/0189/05 \$2.00

Volume 81, January 1988, 189-193 ation with several forms of dominant amyloidosis. The amyloid fibrils in each of these syndromes contain a preponderance of variant prealbumin, which has led to the hypothesis that these genetically abnormal prealbumin molecules are responsible for amyloid formation.

In FAP type I (typified by Portuguese, Japanese, and some Swedish families) the variant prealbumin contains a methionine at position 30 in place of the normal valine (4-6). This syndrome, considered to be the most widespread form, is generally characterized by lower limb neuropathy, bowel dysfunction, and renal failure. The clinical findings are similar in FAP Jewish type but also include vitreous deposits (7), and the prealbumin substitution appears to be an isoleucine for phenylalanine at position 33 (8). The Appalachian type of amyloidosis varies in that neuropathic symptoms are less pronounced and death results from cardiomyopathy (9). The associated prealbumin variant in this type has an alanine in place of threonine at position 60 (10). The Indiana-Swiss (FAP type II) form, which exhibits cardiomyopathy, carpal tunnel syndrome and vitreous deposits, is associated with prealbumin having a serine at position 84 instead of isoleucine (11). The fifth variant described contains a methionine at 111 instead of leucine, and is associated with the hereditary Danish cardiac amyloid (12). This last form generally shows no neuropathy at all.

We report our identification of a new plasma prealbumin variant associated with amyloidosis. This variant, presumed to be the amyloid precursor protein, has a tyrosine at position 77 in place of serine. We have also developed a DNA test (restriction fragment length polymorphism [RFLP]) to detect the gene coding for Tyr-77 prealbumin, and have identified several gene carriers in this family.

\section{Methods}

The 56-yr-old proband (III-3 in Fig. 1) was referred with symptoms of lower limb neuropathy, chronic diarrhea, and periorbital purpura. He is caucasian, of German descent, and most of his family resides in Illinois. Although the family history is not conclusive for amyloidosis, his father (II-1) had similar symptoms and died of renal failure at age $57 \mathrm{yr}$. The proband's grandfather (I-2) died at age $47 \mathrm{yr}$ in an accident, but the grandfather's brother (I-1) reportedly had symptoms identical to the proband (Fig. 1). Sections of a rectal biopsy from the proband were stained with Congo Red, and adjacent sections were stained with anti-human prealbumin (Calbiochem-Behring Corp., La Jolla, CA) using the avidin-biotin immunoperoxidase technique.

Prealbumin was isolated from $100 \mathrm{ml}$ of the proband's plasma by column chromatography as previously described (4). After digestion of $3 \mathrm{mg}$ with $2 \%$ (wt/wt) trypsin, the peptides were separated by HPLC (Synchrom RP-8 column). Amino acid compositions were determined after hydrolysis of the samples with $5.7 \mathrm{~N} \mathrm{HCl}$ under nitrogen for $24 \mathrm{~h}$ at $115^{\circ} \mathrm{C}$. Amino acid analyses were performed on a HPLC system (model 344; Beckman Instruments, Inc., Fullerton, CA) after precolumn derivatization with phenylisothiocyanate (13). Amino acid se- 


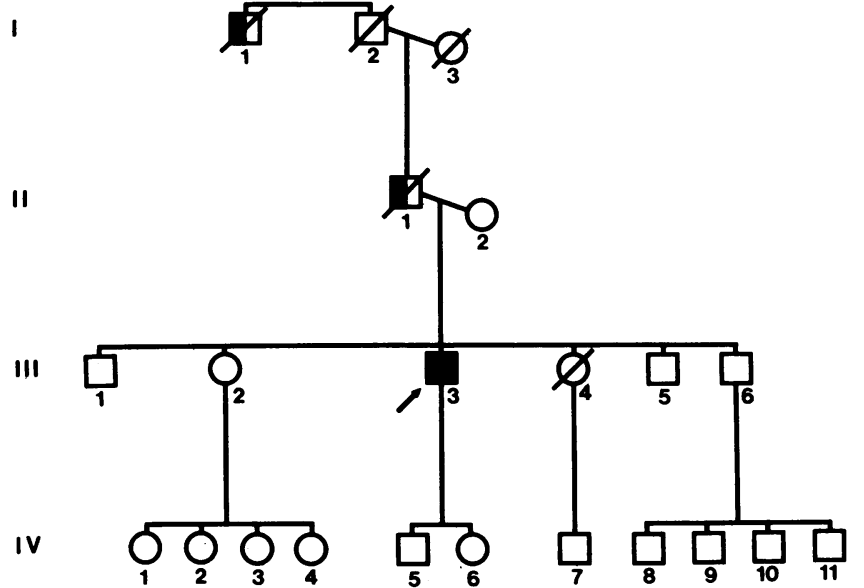

Figure 1. Pedigree of Illinois-German family with hereditary amyloidosis. Circles are females and squares are males. Generation numbers (roman numerals) are to the left and individual numbers are beneath each symbol. The proband (III-3) is indicated by the arrow. Shading indicates proven ( $(\square)$ and suspected ( $\square$ ) cases of amyloidosis, according to the key. For purposes of confidentiality, the pedigree has been slightly altered and nonaffected gene carriers have not been indicated. $\not$, Deceased.

quencing was accomplished with a liquid phase protein sequenator (model 890C; Beckman Instruments) with the $0.1 \mathrm{M}$ quadrol program.

Prealbumin and RBP plasma concentrations were determined by radial immunodiffusion on assay plates from Calbiochem-Behring Corp. (14).

A human chromosome 18 library in Lambda Ch21A (kindly provided by Dr. Marvin Van Dilla, Lawrence Livermore Laboratories) was screened with a human prealbumin CDNA (15) using the method of Benton and Davis (16) with Escherichia coli K802 host cells. One clone (Lambda PA5') containing a 4.7-kb Hind III insert was isolated and determined to contain the $5^{\prime}$ two-thirds of the prealbumin gene. From this, an 850 bp Bam HI-Pvu II fragment was purified from agarose as follows. The block of agarose containing the fragment was excised from the gel, finely minced, vortexed with an equal volume of phenol, and frozen at $-70^{\circ} \mathrm{C}$ for $15 \mathrm{~min}$. After centrifugation the aqueous phase was saved and extracted several more times with phenol and chloroform. The DNA was precipitated and dissolved in water for use as probe. This fragment and a schematic of the prealbumin gene are indicated in Fig. 2.

Genomic DNA was obtained from blood samples from the proband and family members by lysis of red cells followed by lysis of white blood cells and purification of the DNA with phenol and chloroform extractions (17). Southern blot analyses were carried out with the 850 bp probe under conditions described previously (10), after digestion of DNA with Ssp I (New England Biolabs, Beverly, MA).

\section{Results}

Polarization microscopy of Congo Red-stained biopsied rectal tissue from the proband revealed large deposits of amyloid, primarily in blood vessel walls. The deposits showed positive staining with polyclonal anti-human prealbumin (Fig. 3).

From $100 \mathrm{ml}$ of the proband's plasma, $14 \mathrm{mg}$ of prealbumin were purified. The HPLC profile of the tryptic digest was identical to that of normal prealbumin except for the presence of a new peak, peptide $\mathrm{T} 9^{*}$, and a reduction in the normal peak T9 (Fig. 4). These data indicated heterogeneity of T9, with $\sim 40-45 \%$ of these peptides having an increased hydrophobicity and eluting later as T9*. T9 encompases residues 77-80 (Ser-Tyr-Trp-Lys). Except for T9*, amino acid compositions and sequence analyses of all tryptic peptides were identical to normal prealbumin peptides. T9* lacked serine and contained an additional tyrosine. Sequence analysis of T9* gave a sequence of Tyr-Tyr-Trp-Lys. This pinpointed an amino acid substitution, Tyr for Ser, at position 77 of the prealbumin molecule.

Based on the prealbumin cDNA sequence, the only single base change that could account for the Tyr-77 variant is a cytosine (C) to adenosine (A) in the codon for residue 77 (Fig. 5). This hypothesized $C$ to $A$ change creates an Ssp I site where one had not previously existed. According to the normal prealbumin gene sequence (18), exon 3 (encoding amino acids 48-92) resides in a 1.4-kb Ssp I fragment. We predicted that the additional Ssp I cut in the mutant gene would cleave the 1.4-kb fragment into two pieces of sizes $1.1\left(5^{\prime}\right)$ and $0.3 \mathrm{~kb}\left(3^{\prime}\right)$ (Fig. 2).

Preliminary Ssp I Southern analysis using a prealbumin cDNA probe did not reveal any obvious differences between the proband's DNA and normal DNA, except for a reduction in intensity of a 1.4-kb band (data not shown). The 4.7-kb genomic prealbumin clone was then isolated for use as a probe. However, this clone contained a highly repetitive DNA sequence (a 300-bp Alu sequence, indicated in Fig. 2) just upstream of exon 3, and, thus, the complete $4.7-\mathrm{kb}$ insert was unsuitable as a probe. Based on the known gene sequence, an 850-bp Bam HI-Pvu II fragment (Fig. 2) was chosen as probe.
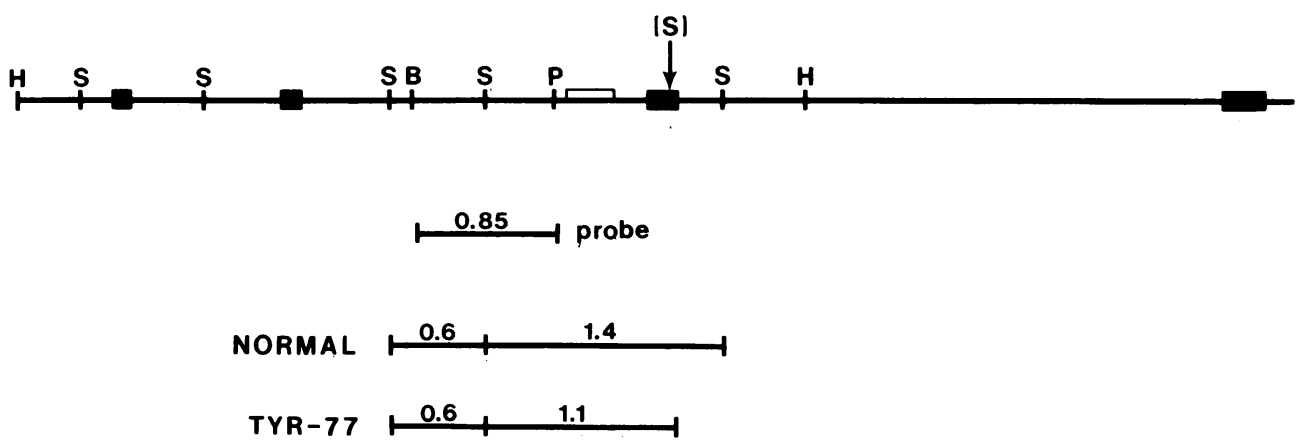

Figure 2. Schema of prealbumin gene, derived $850 \mathrm{bp}$ probe, and DNA fragments from normal and Tyr-77 prealbumin genes detected by the probe. The units for fragment sizes are kilobase pairs (e.g., $1.4 \mathrm{~kb}$ ). The open box represents an Alu sequence. Shaded boxes indicate the exons. S, Ssp I site; B, Bam HI site; $P$, Pvu II site; and $H$, Hind III site. [S] Indicates the Ssp I site created by the Tyr-77 mutation.

The probe should detect a con-

stant 0.6-kb fragment in normal and variant genes, and should detect the variant 1.1-kb fragment (reduced from the normal $1.4 \mathrm{~kb}$ ) in the Tyr-77 gene. 


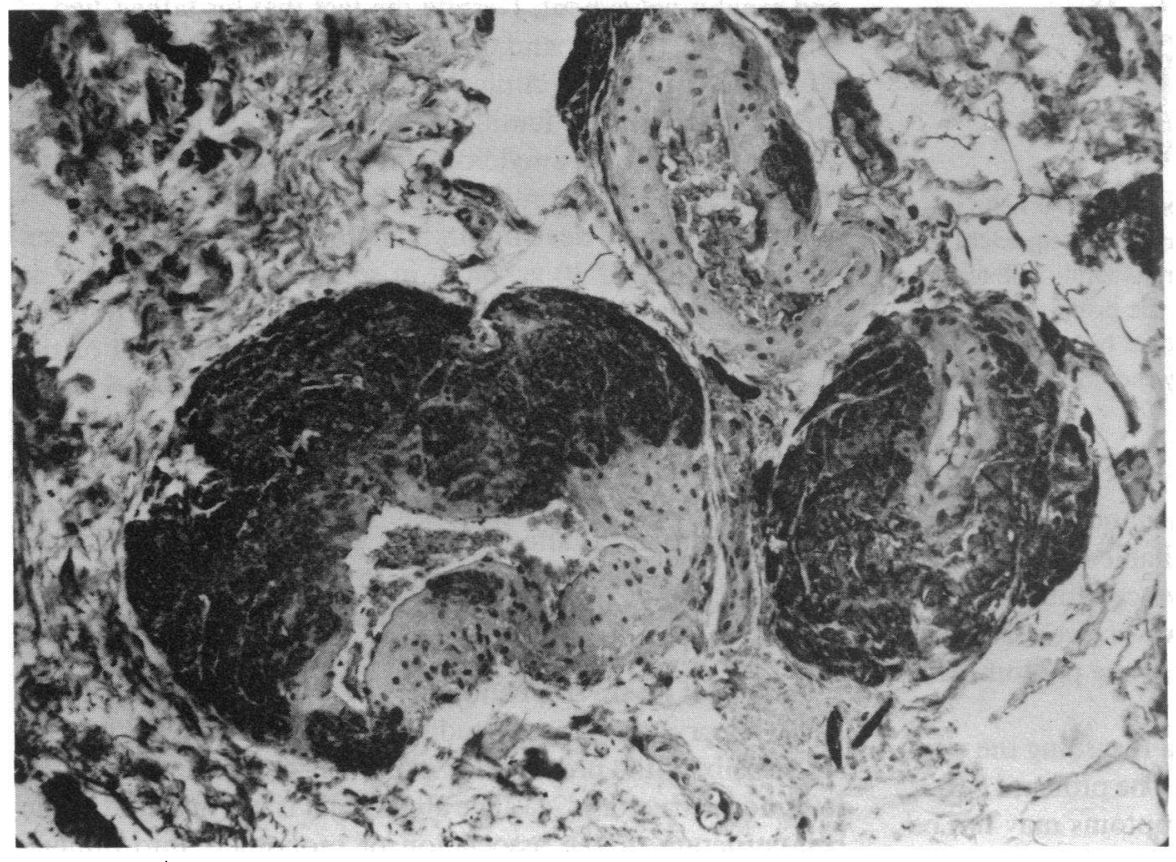

Figure 3. Photomicrograph of the proband's rectal biopsy stained with antiprealbumin using the avidin-biotin peroxidase system. Large vascular deposits (which in adjacent sections were congophilic) are specifically stained. Control sections using a nonspecific antibody (anti-amyloid A protein) showed no staining. $\times 160$.
This fragment is part of intron 2 and spans the Ssp I site that forms the $5^{\prime}$ end of the 1.4-kb fragment. The DNA analysis was repeated using this probe. As expected, the probe detected 1.4-, $1.1-$, and 0.6-kb fragments in the proband, while detecting only 1.4- and 0.6-kb fragments in normal DNA (Fig. 2 and 6). Testing of 15 family members revealed seven with the same DNA pattern as the proband, with the Tyr-77 gene showing Mendelian inheritance. We also tested DNA from eight descendants of I-1, and failed to find any gene carriers.

Because low RBP levels are associated with at least one form of hereditary amyloidosis (14), prealbumin and RBP levels were examined in this family. Plasma prealbumin and
RBP concentrations were within normal limits for all individuals (between 20 and $40 \mathrm{mg}$ prealbumin/dl plasma, and between 3 and $7 \mathrm{mg} \mathrm{RBP/dl} \mathrm{plasma).} \mathrm{Although} \mathrm{the} \mathrm{average}$ prealbumin and RBP levels were somewhat lower in gene carriers $(n=8)$ than in nongene carriers $(n=9)$, there was no clear trend and there were no significant differences from normal.

\section{Discussion}

Our identification of the Tyr-77 prealbumin variant in association with amyloidosis in this kindred is consistent with pre-

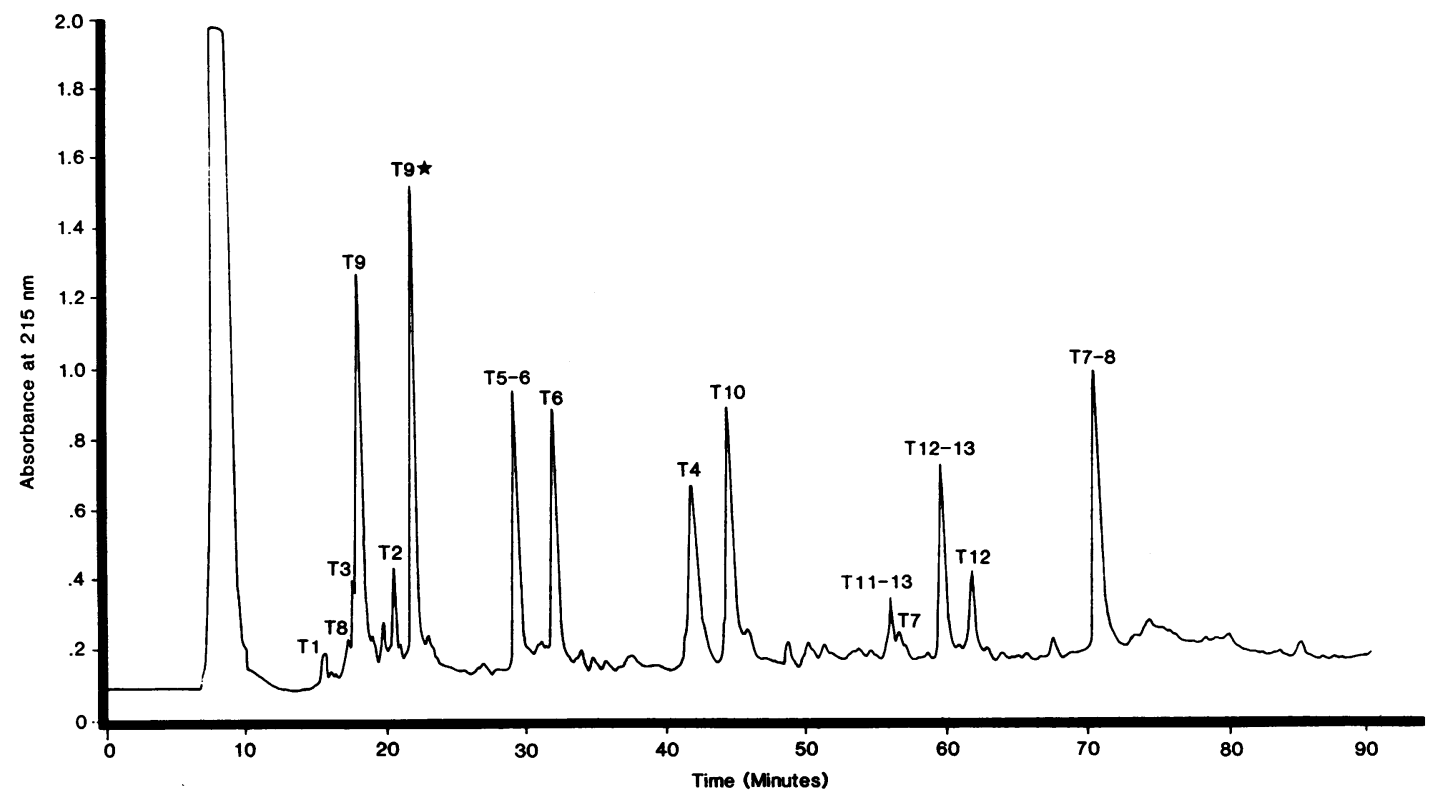

Figure 4. HPLC chromatogram of tryptic digest of the proband's plasma prealbumin. The peaks represent the positions and yields of each tryptic peptide, and are numbered according to each peptide's position in the 127-residue parent molecule (relative to the amino terminus). The profile is identical to that of normal prealbumin except for a new peak, peptide T9*, and a reduction in yield of peptide T9. 


$\begin{array}{cl}\text { amino acids: } & 76 \text { Lys ser Tyr } \\ \text { normal prealbumin gene: } & \text { AAA TCCT TAC } \\ \text { variant prealbumin gene: } & \text { AAA TAT TAC }\end{array}$

Figure 5. Predicted DNA mutation and corresponding Ssp I site in Tyr-77 prealbumin gene. The normal and variant gene sequences of the codon 77 region are given. The only single nucleotide difference that would result in a tyrosine at position 77 in the protein is a $\mathrm{C}$ to A change at the second base of codon 77 (indicated by arrow). The palindromic Ssp I site, coincidentally created by the mutation, is underlined.

vious reports of other prealbumin variants found in hereditary amyloidosis. Since there are no tissues available in large quantity from any patients of this kindred, we cannot study the detailed composition of the amyloid. However, we would expect that the Tyr-77 prealbumin molecule is the predominant protein in the amyloid fibrils.

At this point there are very limited data regarding the clinical syndrome associated with this variant. The proband (III-3) is the only biopsy-proven case, and his symptoms may not be typical for this variant. However, since we found that the proband's mother (II-2) does not carry the mutant gene, we can infer that his father (II-1) was the gene carrier. The father's medical history, which is very similar to that of the proband, can thus be added to the clinical data. Although DNA studies revealed a number of gene carriers in this family, none of these individuals report any symptoms that indicate onset of the disease. All carriers but one (who is 60 -yr old) are under age 50 yr. Several family members report that individual I-1 had the same disorder as the proband; however, we did not find any gene carriers among eight of his descendants, and so cannot be certain that he was a carrier. A number of other branches of the family remain to be studied.

Clinically this syndrome is similar to typical FAP type I (Met-30) with respect to the lower limb neuropathy and bowel

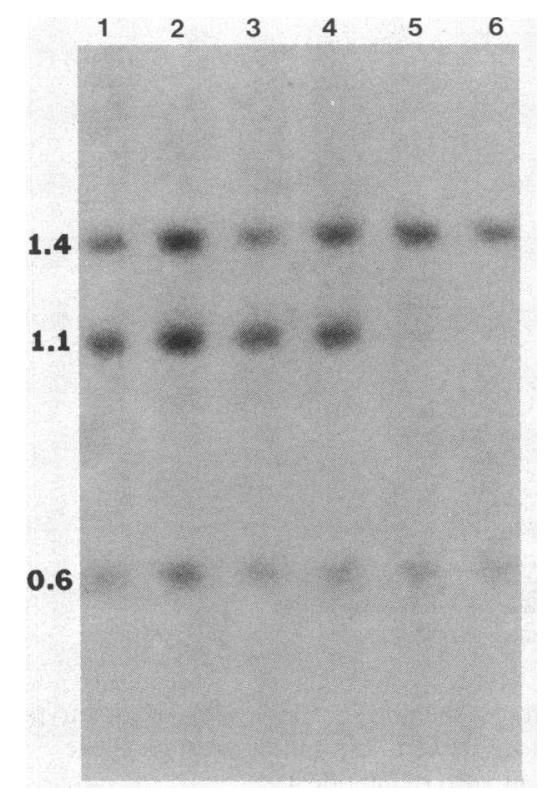

Figure 6. Autoradiograph of DNAs tested for the Tyr-77 prealbumin gene. Each lane represents Ssp I-digested DNA from an individual family member. The DNA was separated through an agarose gel and transferred to nitrocellulose, which was hybridized with the radiolabeled 850-bp prealbumin probe and then exposed to $x$-ray film. The fragment sizes, in kilobases, are listed on the left. Lanes 1-4 contain DNA from carriers of the Tyr-77 mutation, and show the variant 1.1-kb fragment. The two lanes on the right contain normal DNA. and renal involvement. Despite the fact that his father died of renal failure, the proband thus far has normal kidney function. However, significant clinical heterogeneity has been shown even within Met-30 families. Whereas most of the Met-30 kindreds show renal amyloid involvement, at least one family has cardiac involvement without renal abnormality (19). Although the disease develops in many Met-30 patients between the ages of 20 and $30 \mathrm{yr}$, onset in some families can occur as late as the 60 s or 70 s (20). In fact, it has now become obvious with the use of DNA testing that members of several of the kinships (Met-30, Ser-84, Ala-60) can live to advanced age with either no disease or subclinical disease. This adds to the importance of the availability of reliable DNA tests for each of the variants. The limited data in this Tyr-77 kindred would suggest that onset is after age $50 \mathrm{yr}$. The finding of the Tyr-77 variant in a patient with symptoms indistinguishable from those of most Met-30 patients indicates the necessity for complete identification of the amyloid protein in every family, regardless of origin or phenotype.

$\mathrm{X}$-ray crystallographic studies show that residue 77 is in an alpha helix of the prealbumin monomer on the outside of the tetrameric structure (21). The alpha helix is not involved in the beta structure or the association of monomers into dimers. However, the substitution of the much larger tyrosine for serine apparently introduces sufficient structural alteration to make the protein amyloidogenic.

In addition to the biochemical identification of the Tyr-77 variant, we have presented a direct DNA test for gene carriers. Of the five other known prealbumin variants, three have lent themselves to direct RFLP tests. The Met-30 gene can be detected using the enzymes Nsi I or Bal I (22), the Ala-60 test requires the enzyme Pvu II (10), and the Ser-84 gene is detectable using the enzyme Alu I (23). The Met-30 and Ala-60 tests can be done with a prealbumin cDNA probe, in contrast to the Tyr-77 and Ser-84 tests which require genomic probes. The cDNA is therefore of limited usefulness in these types of studies, and in fact the availability of prealbumin genomic clones greatly increases the probability of developing successful DNA tests. Genomic clones will also be useful in the search for random RFLPs in the prealbumin gene, which can be used in chromosome 18 linkage studies and in disequilibrium studies. Direct DNA tests can be predicted for the two other prealbumin variants using the enzymes indicated: Ile-33 (Bcl I or Sau 3A), Met-111 (Dde I).

The only nonprealbumin autosomal dominant systemic amyloidosis reported to date is hereditary cerebral hemorrhage with amyloidosis, in which the amyloid is primarily localized to blood vessels of the central nervous system (24). The amyloid protein in this case is gamma trace (cystatin C) (25). Although the gamma trace in the amyloid contains an amino acid substitution (glutamine at position 58), it also lacks the first ten amino acids of the gamma trace molecule. Also, these patients have extremely low levels of gamma trace in cerebrospinal fluid. It is unclear whether the basis for this disorder is the amino acid substitution, a metabolic error, a transport defect, or combination of these.

Our finding of a sixth prealbumin variant associated with hereditary amyloidosis, along with the finding in hereditary cerebral hemorrhage with amyloidosis, further indicates that hereditary amyloidosis is a group of clinically and biochemically heterogeneous disorders. Evidence now indicates that hereditary amyloidosis is more prevalent than previously 
thought, but is often unrecognized due to its late onset, variable expression, and lack of family history. This AmericanGerman family illustrates this point, as one probable carrier (I-2) died before manifesting the disorder and the diagnosis was missed in another patient (II-1). Determining whether "sporadic" amyloidosis patients actually have hereditary forms is paramount for the families concerned. DNA tests offer relatively simple methods for screening these patients and also offer carrier detection to their families. Future research is likely to identify other prealbumin variants and other proteins involved in hereditary amyloidosis. Also, since families with the same mutation show different syndromes and vice versa, future work will also be aimed at identifying other genetic factors that govern the expression of the disease.

\section{Acknowledgments}

This work was supported by Veterans Administration Medical Research (MRIS 583-0888) and grants from U. S. Public Health Service (RR-00750 [General Clinical Research Center]), National Institute of Arthritis, Diabetes and Digestive and Kidney Diseases (AM 20582, AM 7448, and AM 35482), the Arthritis Foundation, the Grace M. Showalter Trust, the Marion E. Jacobson Fund, and the National Science Foundation. Dr. Wallace is the recipient of an American Fellowship from the Educational Foundation of the American Association of University Women and a John H. Edwards Fellowship from Indiana University.

\section{References}

1. Andrade, C., S. Araki, W. D. Block, A. S. Cohen, C. E. Jackson, Y. Kuriowa, V. A. McKusick, J. Nissim, E. Sohar, and M. W. Van Allen. 1970. Hereditary amyloidosis. Arthritis Rheum. 13:902-915.

2. Costa, P. P., A. S. Figueira, and F. R. Bravo. 1978. Amyloid fibril protein related to prealbumin in familial amyloidotic polyneuropathy. Proc. Natl. Acad. Sci. USA. 75:4499-4503.

3. Robbins, J., S. Cheng, M. C. Gershengorn, D. Glinoer, H. J. Cahnmann, and H. Edelnoch. 1978. Thyroxine transport proteins of plasma. Molecular properties and biosynthesis. Recent Prog. Horm. Res. 34:477-519.

4. Dwulet, F. E., and M. D. Benson. 1983. Polymorphism of human plasma thyroxine binding prealbumin. Biochem. Biophys. Res. Commun. 114:657-662.

5. Tawara, S., M. Nakazato, K. Kangawa, H. Matsuo, and S. Araki. 1983. Identification of amyloid prealbumin variant in familial amyloidotic polyneuropathy (Japanese type). Biochem. Biophys. Res. Commun. 116:880-888.

6. Saraiva, M. J. M., S. Birken, P. P. Costa, and D. S. Goodman. 1984. Family studies of the genetic abnormality in transthyretin (prealbumin) in Portuguese patients with familial amyloidotic polyneuropathy. Ann. NY Acad. Sci. 435:86-100.

7. Gafni, J., B. Fischel, R. Reif, M. Yaron, and M. Pras. 1985. Amyloidotic polyneuropathy in a Jewish family. Evidence for the genetic heterogeneity of the lower limb familial amyloidotic neuropathies. Q. J. Med. 55:33-43.

8. Nakazato, M., K. Kangawa, N. Minamino, S. Tawara, H. Matsuo, and S. Araki. 1984. Revised analysis of amino acid replacement in a prealbumin variant (SKO-III) associated with familial amyloidotic polyneuropathy of Jewish origin. Biochem. Biophys. Res. Commun. 123:921-928.

9. Benson, M. D., M. R. Wallace, E. Tejada, H. Bauman, and B. Page. 1987. Hereditary amyloidosis: description of a new American kindred with late onset cardiomyopathy. Arthritis Rheum. 30:195200.

10. Wallace, M. R., F. E. Dwulet, P. M. Conneally, and M. D. Benson. 1986. Biochemical and molecular genetic characterization of a new variant prealbumin associated with hereditary amyloidosis. $J$. Clin. Invest. 78:6-12.

11. Dwulet, F. E., and M. D. Benson. 1986. Characterization of a transthyretin (prealbumin) variant associated with familial amyloidotic polyneuropathy type II (Indiana/Swiss). J. Clin. Invest. 78:880886.

12. Husby, G., and K. Sletten. 1986. Chemical and clinical classification of amyloidosis 1985. Scand. J. Immunol. 23:253-265.

13. Heinrikson, R. L., and S. C. Meredith. 1984. Amino acid analysis by reverse-phase high-performance liquid chromatography: precolumn derivatization with phenylisothiocyanate. Anal. Biochem. 136:65-74.

14. Benson, M. D., and F. E. Dwulet. 1983. Prealbumin and retinol binding protein serum concentrations in the Indiana type hereditary amyloidosis. Arthritis Rheum. 26:1493-1498.

15. Wallace, M. R., S. L. Naylor, B. Kluve-Beckerman, G. L. Long, L. McDonald, T. B. Shows, and M. D. Benson. 1985. Localization of the human prealbumin gene to chromosome 18. Biochem. Biophsy. Res. Commun. 129:753-758.

16. Benton, W. D., and R. W. Davis. 1977. Screening lambda-gt recombinant clones by hybridization to single plaques in situ. Science (Wash. DC). 196:180-182.

17. Madisen, L., D. I. Hoar, C. D. Holroyd, M. Crisp, and M. E. Hodes. 1987. DNA banking: the effects of storage of blood and isolated DNA on the integrity of DNA. Am. J. Med. Genet. 27:379-390.

18. Tsuzuki, T., S. Mita, S. Maeda, S. Araki, and K. Shimada. 1985. Structure of the human prealbumin gene. J. Biol. Chem. 260:12224-12227.

19. Kincaid, J. C., M. D. Benson, F. E. Dwulet, P. R. Greipp, and R. L. Lautzenheiser. 1984. A new family with hereditary amyloidosis. Clin. Res. 32:821A. (Abstr.)

20. Saraiva, M. J. M., P. P. Costa, and D. S. Goodman. 1986. Genetic expression of a transthyretin mutation in typical and lateonset Portuguese families with familial amyloidotic polyneuropathy. Neurology. 36:1413-1417.

21. Blake, C. C. F., M. J. Geisow, and S. J. Oatley. 1978. Structure of prealbumin: secondary, tertiary and quaternary interactions determined by Fourier refinement at 1.8 angstroms. J. Mol. Biol. 121:339356.

22. Sasaki, H., Y. Sakaki, H. Matsuo, I. Goto, Y. Kuriowa, I. Sahashi, A. Takahashi, T. Shinoda, T. Isobe, and Y. Takagi. 1984. Diagnosis of familial amyloidotic polyneuropathy by recombinant DNA techniques. Biochem. Biophys. Res. Commun. 125:636-642.

23. Wallace, M. R., F. E. Dwulet, P. M. Conneally, and M. D. Benson. 1987. A direct DNA test for Indiana/Swiss hereditary amyloidosis (FAP type II) (prealbumin variant Ser-84). Clin. Res. 35:419A. (Abstr.)

24. Gudmundsson, G., J. Hallgrimsson, T. A. Jonasson, and O. Bjarnason. 1972. Hereditary cerebral haemorrhage with amyloidosis. Brain. 95:387-404.

25. Ghiso, J., B. Pons-Estel, and B. Frangione. 1986. Hereditary cerebral amyloid angiopathy: the amyloid fibrils contain a protein which is a variant of cystatin $\mathrm{C}$, an inhibitor of lysosomal cysteine proteases. Biochem. Biophys. Res. Commun. 136:548-554. 